\title{
BARCELONA, POSA'T GUAPA ${ }^{\star}$
}

\author{
Károl Veiga Cabral $\star$

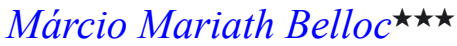

\section{RESUMO}

A partir de um percurso por Barcelona, assumindo a postura do flâneur, buscamos refletir sobre a constituição de propostas distintas de viver de habitar a cidade. A primeira se refere a um projeto institucional que se impõe, propondo um modelo Barcelona Guapa, na qual se pode observar uma clara tentativa de privatizar e domesticar uma cidade. A segunda diz respeito às formas de resistência possíveis a esta tentativa institucional. O percurso, que se inicia em um bairro às margens do Mediterrâneo, tem seu apogeu no coração da cidade, um lugar de pluralidade, espaço de criação, invenção e resistência chamado Radio Nikosia.

Palavras-chave: experiência urbana; resistência; comunicação; intervenção política; acontecimento.

\section{BARCELONA, POSA'T GUAPA}

\begin{abstract}
From a route by Barcelona, assuming the posture of the flaneur, we aim to reflect on the formation of different proposals for habiting in the city. The first refers to an institutional project that is required proposing a model Barcelona Guapa, which can see a clear attempt to tame and privatize a town. The second concerns the possible forms of resistance to this attempt institution. The route that starts in a neighborhood on the shores of the Mediterranean has its heyday in the heart of the city, instead of plurality, a space for creation, invention and resistance named Radio Nikosia.
\end{abstract}

Keywords: urban experience; resistance; communication; policy intervention; development.

^Apoio do Programa Alßan, Programa de Bolsas de Alto Nível da União Europeia para América Latina, bolsa $\mathrm{n}^{\circ}$ E07D400822BR.

$\star \star$ Doutoranda em Antropologia pela Universitat Rovira i Virgili, Tarragona, Espanha; Mestre em Psicologia Social e Institucional pela Universidade Federal do Rio Grande do Sul; membro da Asociación Cultural Radio Nikosia. E-mail: karolveigacabral@gmail.com

$\star \star \star$ Doutorando em Antropolgia pela Universitat Rovira i Virgili, Tarragona, Espanha; Mestre em Artes Visuais pela Universidade Federal do Rio Grande do Sul; membro da Asociación Cultural Radio Nikosia.

E-mail:mmbelloc@gmail.com 
Barcelona, primeiro de abril de 2009. São duas horas da tarde, dos del medio día, como se diz por aqui. A maioria das pessoas se prepara para almoçar e os que podem e têm o costume já imaginam o tradicional momento do sono recuperador da ciesta. Neste dia nós não podemos acompanhar tal tradição; nos espera a aventura semanal de um espaço de liberdade, de intervenção política e, sobretudo, de criação. Todas as quartas-feiras emitimos desde a Contrabanda $\mathrm{FM},{ }^{1}$ um programa que se chama Rádio Nikosia. ${ }^{2}$

Nosso percurso até a rádio não é propriamente longo, são apenas uns 20 minutos em um passo lento que permita uma caminhada em um ritmo inspirado pelo flâneur benjaminiano, ou seja, o colecionador de sensações da grande cidade, um sonhador de imagens de desejo e fantasmagorias.

A multidão é seu universo, como o ar é o dos pássaros, como a água, o dos peixes. Sua paixão e profissão é desposar a multidão. Para o perfeito flâneur, para o observador apaixonado, é um imenso júbilo fixar residência no numeroso, no ondulante, no movimento, no fugidio e no infinito. Estar fora de casa, e, contudo sentir-se em casa onde quer que se encontre; ver o mundo, estar no centro do mundo e permanecer oculto ao mundo, eis alguns pequenos prazeres desses espíritos independentes, apaixonados, imparciais (BAUDELAIRE, 1988, p.170).

Nesse curto espaço de tempo, somos invadidos por distintas imagens e signos de uma cidade como Barcelona. Vamos ao nosso percurso!

Moramos em um bairro chamado Barceloneta. Quando Barcelona ainda era uma cidade murada este lugar nem existia. As primeiras edificações foram construídas em 1754 e o bairro foi sendo habitado por pescadores e pessoas relacionadas com as atividades portuárias da zona, que viviam em condições precárias. A estrutura dos edifícios se mantém praticamente a mesma, com a exceção de alguns prédios mais contemporâneos, dividindo a atmosfera de sal e mar com luxuosos hotéis, cassinos e caros restaurantes que nasceram com o advento das Olimpíadas de 1992. Nesse período a praia é inventada. O que antes eram pedras agora recebe uma faixa de areia da montanha construindo uma orla artificial, habilitada para o turismo de praia. Com isso, o antigo bairro de pescadores, que outrora foi também lugar de chabolas, moradia de gitanos e espaço privilegiado de música e dança, às margens do Mediterrâneo, ao lado do Porto Velho, é hoje alvo da especulação imobiliária e do turismo predatório, que na verdade afeta toda a cidade de Barcelona. Como nos aponta Milton Santos:

O espaço, portanto, torna-se a mercadoria universal por excelência. Como todas as frações do território são marcadas, doravante, por uma potencialidade cuja definição não se pode encontrar senão a posteriori, o espaço se converte numa gama de especulações de ordem econômica, ideológica, política, isoladamente ou em conjunto (SANTOS, 2004, p. 30). 
Mas esse bairro simples, cheio de mesclas, e com sonoridade e cheiro peculiares, ainda consegue manter sua cara de aldeia, sua distância da Barcelona guapa que tanto se quer vender. Há aqui, em suas ruas estreitas de janelas e sacadas pequenas adornadas com a roupa para secar, um movimento de resistência da comunidade local, que luta para preservar a história, a arquitetura, os hábitos e ,principalmente, os moradores de tantos anos. Mais do que isso, a luta é pela preservação da diversidade cultural, a mistura que faz da Barceloneta um dos poucos bairros ainda vivos desta cidade. Caminhando, passamos pelas ruas estreitas e avistamos as pessoas em suas atividades mais corriqueiras do dia-a-dia; umas conversam desde as suas sacadas enquanto estendem a roupa, outras caminham cumprimentando as pessoas que passam, a senhora da casa de frutas lembra que as cerejas estão estupendas, a sonoridade das palmas de um grupo de pessoas em um bar, mescladas com o cheiro característico de orujo, invade o espaço da rua e lembra ainda que este lugar preserva suas cores ciganas. Atravessamos a Praça de La Font na qual se encontra o mercado da Barceloneta. Antigamente todos os bairros da cidade possuíam seu próprio mercado, com várias bancas de produtos a preços populares. Hoje, tais lugares também enfrentam a especulação imobiliária vigente. Muitos foram remodelados e já não possuem preços populares como outrora. Encontramos uma banca de jornal na qual está grafitado a seguinte frase: La belleza es tu cabeza.

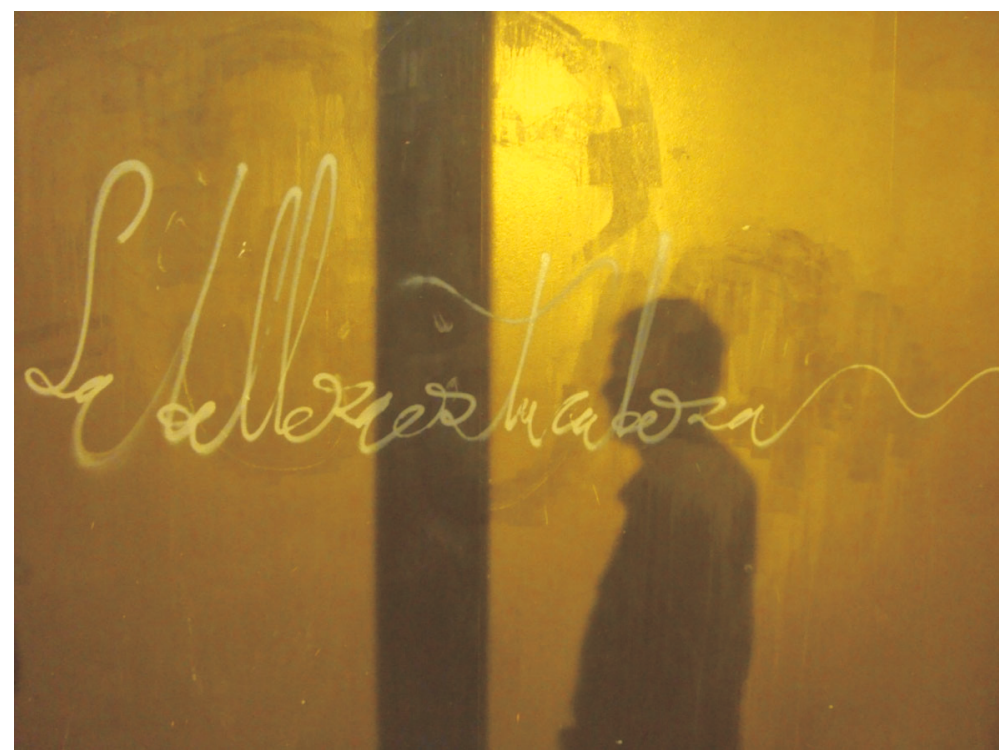

Figura 1: Cabral - La belleza es tu cabeza 1, 2009

Esta frase pode ser encontrada em outros tantos pontos da cidade, mesmo nos lugares mais inusitados, tais como uma caixa de correio, uma banca de sorvetes e até nas caixas de fiação. Frase que produz uma imediata reflexão e uma contraposição com o convite governamental de transformar a Barcelona em guapa. Onde está a beleza? Quem a produz? 


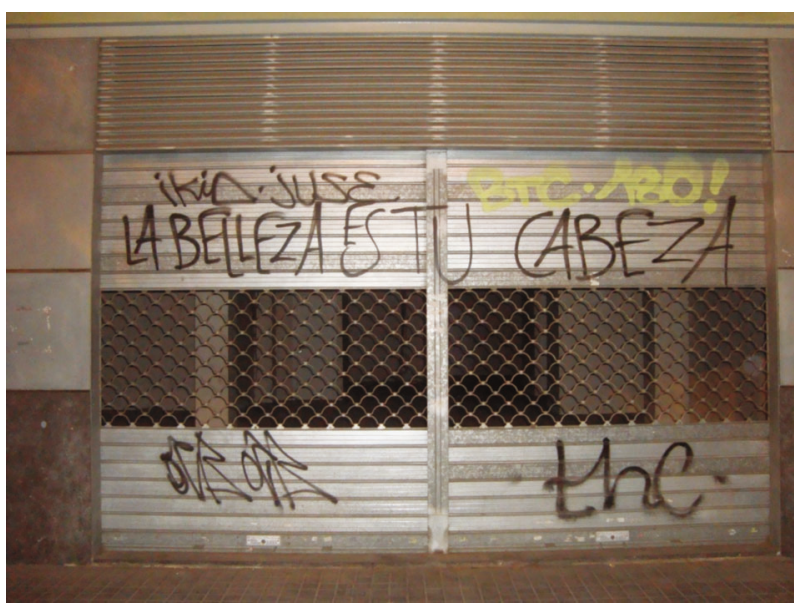

Figura 2: Cabral - La belleza es tu cabeza 2, 2009

Cruzamos a grande Avenida Joan de Borbó e somos assaltados pela imagem forte dos senegaleses vendendo suas bolsas de "grife" ao lado do Porto Velho. Imagem que nos arranca da sonoridade gitana e nos arrasta a pensar sobre os fluxos migratórios que trazem milhares de africanos todos os anos à costa europeia na perspectiva de uma vida melhor. Pessoas que cruzam o mar em pateras, desde a costa africana, por um preço tão elevado que até mesmo pode lhes custar a vida, como se pode confirmar no filme chamado 14 Quilômetros (2007), produção espanhola dirigida pelo cineasta Gerardo Olivares.

Em meio a uma das mais duras realidades das migrações atuais - posto que não é a única das vicissitudes que a condição estrangeira impõe - , nos invade a memória de um encontro casual de uns poucos dias atrás. O lugar era uma lavanderia do bairro, dessas automáticas em que o cliente se encarrega do trabalho, operando máquinas de lavar e secar apertando botões e inserindo moedas. Distraídos pela leitura de um jornal, à espera do término do ciclo de lavagem, não vimos entrar a senhora já idosa, que com sua expressão de surpresa, suas sacolas de roupas, sua moedeira preparada na mão esquerda, não sabia como pôr em funcionamento o processo moderno e automático de lavagem. É ela que nos pede auxílio, e é prontamente atendida. Quando já as roupas se volteiam em meio à espuma, ela se senta e, depois de muitos agradecimentos, começa a contar sua história. Inicia dizendo que sempre viveu

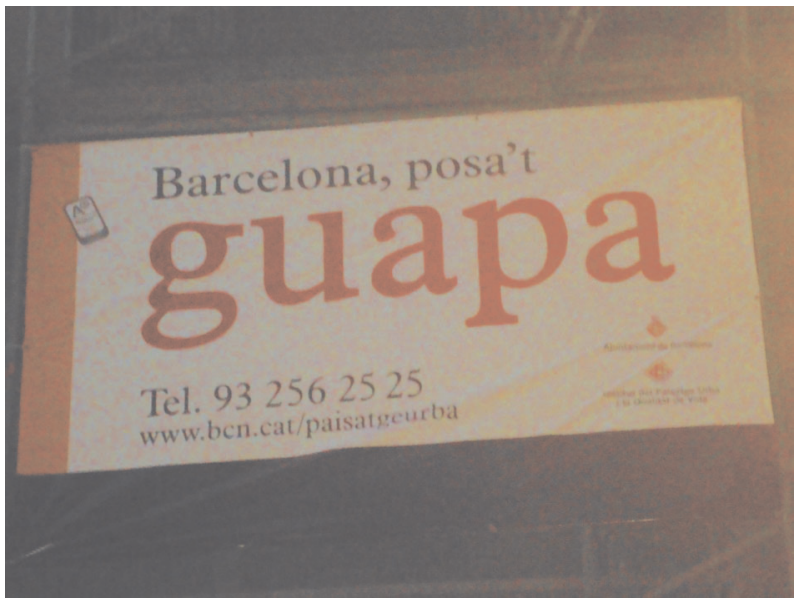

Figura 3: Cabral - Barcelona posa 't guapa, 2009 na Barceloneta e que é testemunha de todas as suas mudanças. Diz que hoje se sente quase como uma estrangeira de tão distinta que sua Barceloneta da infância está. Conta da gente simples, das crianças e suas correrias pelas ruas, do seu pai re- 
mendando uma rede de pesca na calçada, das portas abertas, sempre abertas, para que as pessoas passem e para que a brisa do mar refresque a casa. Conta também do alvoroço que se ouvia a partir de 1936, no início da guerra civil, da revolução que as ruas catalanas protagonizaram. Conta com os olhos marejados de 1939, ela ainda muito jovem, da cidade que vivia sob a guerra, e de outra correria pelas ruas da Barceloneta, quando explodiram os bombardeios alemães, parceiros de Franco, que destruíram parte dos prédios. Esta senhora de mãos enrugadas e sorriso franco fala dos bombardeios como um prenúncio mortal de uma mudança da qual seria testemunha ao longo dos anos. Sua vizinhança da infância era agora também lugar de veraneio de ricos europeus do norte.

Um saboroso cheiro de frutos do mar nos faz voltar à realidade que nos cerca, já que estamos caminhando ao lado do porto, com seus restaurantes sofisticados repletos de turistas. Roupas coloridas, câmeras de fotos e gente sorridente passeia ao lado de não menos luxuosos barcos ancorados. Em meio a tudo isso, avistamos o carro dos mossos d'esquadra, a polícia local, e os vendedores de rua correm em disparada, levando seus pára-quedas com as mercadorias rua a fora. Nada acontece, ninguém é preso, mas o ritual é cumprido, a polícia faz o seu papel e os vendedores ambulantes também. As ruas ficam 'limpas' e os turistas podem voltar ao seu coqueteio habitual. Trocamos um sorriso e seguimos caminhando, "isto é Barcelona", pensamos. Logo após os restaurantes, existe uma série de tendas de comércio legal, assim como músicos de rua forçosamente legalizados em meio a uma onda de civismo que invadiu há alguns anos a cidade.

Para identificar um ponto de referência dessa onda, podemos aludir à Ordenanza de medidas para fomentar y garantizar la convivencia ciudadana en el espacio público de Barcelona. ${ }^{3} \mathrm{O}$ objetivo principal, disso que ficou conhecido como lei de civismo e que entra em vigor em 2005, seria o de preservar o espaço público como um lugar de convivência e civismo, no qual todas as pessoas possam desenvolver em liberdade suas atividades de livre circulação, de ócio, de encontro e de recreio, com pleno respeito à dignidade e aos direitos dos demais $\mathrm{e}$ à pluralidade de expressões e de formas de vida diversas existentes em Barcelona. Esta Ordenanza atua dentro do âmbito de competências de que dispõe o Ayuntamiento de Barcelona ${ }^{4}$ com o fim de evitar todas as condutas que possam perturbar a convivência e minimizar os comportamentos incívicos que se possam realizar no espaço público. Esse texto legal, então, identifica quais são os bens jurídicos protegidos, prevê quais são as normas de conduta em cada caso e sanciona aquelas que possam perturbar, lesar ou deteriorar tanto a própria convivência cidadã, bem como os bens que se encontram no espaço público, prevendo, no caso, medidas específicas de punição e intervenção.

Contudo, apesar de o texto falar de pluralidade de expressões e liberdade, a prática de emprego dessa Ordenanza parece ter-se dirigido mais à aplicação de normas de conduta cívicas e limpeza do espaço urbano para a livre circulação, tanto de moradores como, também, e, principalmente, de turistas. A tentativa é de controle pleno do espaço público, de suas manifestações, numa clara busca de privatização do mesmo. Privado da pluralidade e liberdade, apto para a livre circulação de veículos e de gente civilizada-domesticada, seja morador ou seja turista. 
Hannah Arendt, em sua célebre Condição Humana de 1958, nos ensina que o conceito de vida privada deve ser pensado como aquele em que estamos literalmente privados do convívio entre os homens, o espaço doméstico. O espaço público por excelência seria o do exercício político no qual os homens, sob o manto da pluralidade, estão livres para discutir e construir uma cidade que, justamente pela característica plural que a alimenta, é sempre inventada e reinventada em cada ação, em cada acontecimento que irrompe de sua vida pulsante. Tomando a Atenas de Péricles como modelo, apesar de serem poucos os verdadeiros cidadãos, os homens livres que exerciam a política, nesta a lei deveria ser entendida como um muro de proteção para o exercício político, da pluralidade e da liberdade.

Voltando ao nosso percurso pelas ruas barcelonesas, quase chegando ao Passeio Colom, a escultura de Roy Lichtenstein, a Cabeça de Barcelona (1992), nos sorri. Sua estrutura tridimensional em branco, vermelho, azul e amarelo é como um pingo de modernidade em meio a prédios antigos como o dos Correos, entre outros, que compõem a fronteira com o Bairro Gótico. Metemos-nos por suas ruelas estreitas, por vezes quase sinistras de tão escuras e bolorentas, mas também de uma beleza própria do que aqui se chama cidade velha. Caminhando pela Rua Avinyo somos convocados a um novo contraste. Seus prédios antigos que já viram passar alguns séculos hoje abrigam lojas de design, as últimas tendências para os descolados podem ser encontradas nas vitrines desse bairro. São como estilhaços das cores e brilhos da escultura de Lichtenstein. Seguimos, estamos no meio do caminho. A diversidade das cores das vitrines deambula pelas ruas da cidade, garantindo uma aparência cosmopolita.

Dobramos à esquerda na Rua Escudellers e nos deparamos com a Praça George Orwell. Essa rua leva o nome do escritor que nos anos 1930 abandonou a segurança de sua casa para lutar nas frentes republicanas espanholas e hoje protagoniza um espaço de resistência, encontro de músicos, de moradores de rua, de pessoas anti-sistema, e é conhecida popularmente como a Praça Trip. Neste local existe uma escultura de aço retorcido, com uma esfera amarela que parece flutuar e dá uma sensação de possível movimento giratório. Existem outras esculturas como esta espalhadas pela cidade. Em um determinado momento tais locais foram tomados pelo movimento urbano como pontos de consumo e venda de substâncias psicoativas consideradas ilegais. O nome pelo qual atualmente a praça é conhecida alude à substância que ali era mais consumida: Trip, uma droga de design, que significa viagem, uma mescla de diferentes substâncias que multiplicam seus efeitos.

Essa praça pode ser vista como uma das muitas ilhas que flutuam pela cidade, como guetos de resistência e de irreverência, como tentativas de subversão do instituído, de não submissão. Pontos chaves, que possibilitam aberturas, por vezes na radicalidade de uma saída que se esgota no evento, que não perdura, mas mesmo assim não deixa de produzir efeitos. Revela também uma Barcelona das entrelinhas, do não dito, já que não é bonito (guapo), mas que se dá a ver, como diria Manuel Delgado (2007, p. 40): 
la clave ahí está siempre en los dinteles de visibilización máxima, exposición a y en un mundo en que todo lo que está presente se da a mirar, ver, observar desde una mirada por definición móvil, ejercida durante y gracias a la locomoción y el desplazamiento.

Para este autor, Barcelona é uma cidade que nesses últimos anos tem vivido uma grandiosa experiência política e urbanista que está orientada pela obsessão, pela coerência e pela legibilidade que acaba por tentar controlar o que de fato é incontrolável, ou seja, os ruídos, as misérias, as paixões, os desacatos, as rebeldias, as injustiças etc. É todo esse emaranhado de indefinições que compõem uma cidade. De fato, tudo aquilo que não convém ao modelo Barcelona guapa, ou seja, uma cidade feita de poder e feita de dinheiro.

Esta frase escrita em catalão, Barcelona, posa't guapa, que dá título ao presente artigo e que se pode encontrar em vários pontos da cidade, na qual uma obra de restauração urbana está em marcha, cuja tradução literal seria "Barcelona, ponha-te bonita", é o lema de uma Campanha para a Proteção e Melhoria da Paisagem Urbana. ${ }^{5}$ É uma campanha do Ayuntamiento de Barcelona. Seu objetivo, segundo as linhas gerais que a regem, seria o de estimular, fomentar e impulsionar as atuações de manutenção e reabilitação do patrimônio privado da cidade. Assim, a partir de um conjunto de programas de subvenções para a reabilitação interior e exterior dos imóveis, bem como a melhoria da acessibilidade às instalações, a proposta final seria a de aprimorar a qualidade de vida dos cidadãos barceloneses, com o propósito de incidir no desenvolvimento sustentável da cidade.

O grande risco apontado por Delgado, em relação à transformação urbanística de Barcelona, é de que políticos, arquitetos e urbanistas, na perspectiva de submeter o espaço urbano, de domá-lo para que se converta nesse modelo aparentemente ideal, acabe desativando uma das cidades mais apaixonantes e apaixonadas da Europa.

Continuando em nossa caminhada, chegamos à Praça Real, situada no coração da cidade, ao lado das Ramblas, a mais famosa peatonal de Barcelona, lugar que abriga restaurantes, bares, casas de espetáculos, hotéis e também a sede da Contrabanda FM, uma rádio livre, não comercial, assembleária e autogestionada, que emite nas ondas barcelonesas desde 1991, composta por uma série de pessoas e coletivos unidos pelo desejo de fazer rádio. E desde aí que emitimos o programa de Nikosia, todas as quartas-feiras em sua abertura lemos um texto que inicia o programa:

Nikosia é a última cidade dividida. Por muralhas, ideias, religiões e um suposto abismo cultural. Acreditamos que de uma maneira ou outra todos levamos certa Nikosia dentro da geografia do corpo e da mente. Alguém separou em dois a Nikosia, mas nós viajamos constantemente de um lado a outro desta fronteira. E é desde este dualismo, desde este vaivém que vamos aqui contar nossa história que é tão real e legítima como qualquer outra (CABRAL; BELLOC, Rádio Nikosia). 
Faz um pouco de frio, apesar de ser primavera, chegamos finalmente à rádio e também os redatores vão chegando pouco a pouco. O programa de hoje é sobre o tema das Ilusiones, que já nos rendeu um intenso debate na segunda-feira, dia em que realizamos as assembleias desse coletivo e que trabalhamos o tema do próximo programa. O coordenador do mesmo, que, via de regra, é a pessoa que sugeriu o tema, diz em que perspectiva pensa em desenvolver o assunto e todos lançam suas ideias e diferentes olhares sobre o mesmo, de modo que podemos ter uma pálida noção do debate de quarta-feira. Dizemos pálida porque, quando se trata dos redatores de Nikosia os temas podem sofrer profundas transformações e receber distintos tratamentos em tão pouco tempo. E assim porque somos um coletivo vivo, que pulsa, que se transforma, que não resiste ao novo, deixa fluir, se permite o prazer de provar. Os redatores vão ocupando seu espaço: uns no estúdio, de onde se transmite o programa ao vivo, enquanto outros se sentam pela sala na qual realizamos as reuniões, esperando o momento de entrar no estúdio para falar. Outros ainda podem estar pela cozinha aquecendo água para uma infusão, ou mesmo para o mate. A luz vermelha se acende, estamos no ar, não há tensão e sim compenetração, compromisso e satisfação por poder emitir todas as semanas um programa diferente, que dá voz a pessoas historicamente silenciadas e desacreditadas. Pessoas que, em algum momento, receberam a etiqueta de enfermos mentais e que desde então, foram segregadas ao mundo dos sem palavras, dos sem razão, dos inaptos para o exercício da cidadania. Nesse espaço das ondas da rádio diariamente retomamos o poder da palavra, a possibilidade de refletir e compartilhar nossas experiências com os demais, retomamos nosso lugar de direito, o lugar de cidadão, pelo respeito à pluralidade na constituição de um espaço de discussão e luta contra o estigma, em que todos, diagnosticados ou não, con $o$ sin papeles, como costumamos dizer em Nikosia, têm o mesmo espaço de fala, de poder. Antes de tudo é a constituição de um espaço de cumplicidade que cria um lugar de fala e, principalmente, de intervenção política. Cumplicidade que dobra e redobra a cidade pelas ondas radiofônicas.

O coordenador do programa se preocupa em dar espaço para que todos falem, primeiramente nomeando cada um dos presentes pelas instalações da rádio e também aqueles que fazem parte desse coletivo, mas que, por algum motivo, não puderam estar presentes no momento do programa. Chama a todos para cumprimentarem os ouvintes no ar, manda um alô caloroso a todas as rádios parceiras espalhadas pelo mundo e comenta um pouco o tema do dia, lembrando sempre nossos meios de contato para que as pessoas que nos escutem possam participar do programa, chamando ao vivo, mandando mensagens pela web etc. Ressaltamos esse convite à palavra, esse convite à participação. Talvez isto seja justamente o que falte a esta cidade neste momento, a participação popular, vozes que se unam e que se levantem pra reclamar, discutir, propor e encaminhar assuntos que concernem ao fato de viver em uma grande cidade. Faz-nos lembrar a frase de uma música de um dos muitos grupos musicais parceiros de Nikosia que cantavam nas ruas da cidade, chamado Che Sudaka ${ }^{6}$ que convida "Almas rebeldes levantense", convocando os insatisfeitos a reclamar por algo. Voltar a ocupar o 
espaço da polis, reclamar por ele, pensá-lo e, então, transformá-lo. "El espacio es una duda: continuamente necesito marcarlo, designarlo; nunca es mío, nunca me es dado, tengo que conquistarlo" (PEREC apud DELGADO, 2007, p. 27).

Não nos parece que lançar um projeto que leva o nome Barcelona posa't guapa, de fato vá transformar uma cidade em algo belo. Na verdade, estamos mais de acordo com o grafiteiro que sorrateiramente quebra as normas civis estabelecidas e escreve em diferentes espaços da cidade para que todos possam ler que a beleza está em nossas cabeças, naquilo que pensamos, em nossa capacidade de reflexão. Cabe lembrar que, em cada prédio no qual se faça uma restauração ou uma melhoria, encontramos gravado na tela de proteção que envolve o mesmo a frase da Barcelona bonita, ou seja, Barcelona posa't guapa. Tampouco nos parece ruim restaurar antigos prédios. Na verdade é também uma forma de manter a memória cultural, de preservar o passado. $\mathrm{O}$ que nos provocou a escrever sobre este fato e apontar esse contraste entre posar como bonita e pensar a beleza, é justamente a possibilidade de convidar as pessoas a pensar sua cidade, a participar. Sair de uma relação privada com a cidade e mergulhar na polis.

Além de preservar o patrimônio histórico-arquitetônico da cidade, nos alimentamos das teses sobre história de Walter Benjamin, e pensamos que preservar o passado é captar a configuração que o tempo presente entrou em contato com uma época anterior e, dessa maneira, fundar um "conceito de presente como um 'agora' no qual se infiltram estilhaços do messiânico” (BENJAMIN, 1994, p. 232).

Seja a partir dessa espécie de ágora torta nikosiana que se reinventa a cada programa; seja a partir das memórias da senhora da lavanderia, que em suas múltiplas correrias infantis nos reatualiza a correria dos senegaleses que buscam um espaço de sobrevivência com sua forma de comércio; seja a partir das viagens resistentes impulsionadas pela Praça Trip; seja a partir do grafiteiro que deixa sua reflexão espalhada pela cidade; algumas vozes se fazem ouvir, reclamando a uma outra Barcelona. Uma Barcelona que se erige dos estilhaços messiânicos que se infiltram neste agora promovido por tais vozes. E aqui podemos reencontrar o tema discutido no programa citado. O termo Ilusión em espanhol é usado com o sentido de desejo, significando um anseio, algo a ser buscado. Pois o conceito de messiânico, Benjamin o retira da tradição judaica, na qual o messias está sempre por chegar, está sempre no vir-a-ser. Dessa forma, tais estilhaços são de desejos, de anseios, de futuro, de um horizonte que inspira e constrói o caminho a ser traçado.

São quase seis horas da tarde em Barcelona, o programa se encaminha para o final, durante as duas horas de transmissão ao vivo aconteceram muitas coisas, reflexões, debate, poesia, música, entrevistas, notícias etc. O coordenador começa a despedir-se dos ouvintes agradecendo as participações, as chamadas telefônicas, as mensagens por e-mail enviadas à rádio e àqueles que nos acompanharam escutando o programa ao vivo. Aproveita para lançar o tema da próxima quartafeira e convida a todos a nos acompanharem pela rádio ou pela web. Finalizamos com uma música de um outro grupo musical que toca pelas ruas de Barcelona chamado Microguagua, ${ }^{7}$ também nossos parceiros. A música que é transmitida 
pelas ondas da rádio faz uma crítica à cidade e convida à reflexão e a uma tomada de posição. Reflexão e ação! Este é o convite. Acreditamos que toda quarta-feira lançamos pelo ar uma onda que convida ao acontecimento.

Podemos pensar o acontecimento, como nos ensina Valadares (2003),como possibilidade de encontro e, para que tal aconteça, deveremos ter a coragem de viver o acontecimento e de perder algo de si neste encontro com o outro, com a alteridade. Assim, o acontecimento poderá ser entendido como nada mais que um corte, uma ruptura, com aquilo que, de certo modo, paralisa e enclausura o sujeito em uma dada posição. Segundo este autor, não devemos confundir evento com acontecimento, pois o evento poderá ser grandioso, mas não produzir nada em termos de acontecimento, ou seja, em termos de ruptura, de transformação, de rotação.

Bem sabemos que só é possível ao sujeito enunciar algo de singular a partir da inscrição no laço social. A grande alienação que assistimos atualmente está diretamente ligada ao delírio de independência, ao encastelamento narcísico no qual se encontra o sujeito moderno, à privatização do espaço público.

Do elevador à garagem subterrânea, desta à auto-estrada e novamente à garagem e elevador; a circulação pelo urbano, longe de engajar o corpo no encontro com a diversidade lança-o na cômoda monotonia do individualismo (PALOMBINI, 2004, p. 33).

Assim, o sujeito moderno é levado a acreditar que o individualismo é a grande liberdade, porquanto se enreda nas teias da alienação, preso a seu próprio narcisismo e a um engodo de liberdade que , na verdade, o domestica e aprisiona. Dessa forma, o encontro com o outro se torna secundário e muitas vezes até evitado, pois o olhar do outro pode desestabilizar tal postura narcísica. O que buscamos através da rádio é promover encontros que tenham a força do acontecimento, que provoquem rupturas no instituído, que convoquem a todos e a cada um a assumir uma postura mais participativa na construção de uma cidade bela não só por sua arquitetura, mas também, tendo como horizonte um tipo de beleza que aceite a pluralidade, que busque o encontro, que promova acontecimentos. Segundo Arendt (1997, p. 72):

Desde una perspectiva teórica lo decisivo es que la libertad no se localice ni en el hombre que actúa y se mueve libremente ni en el espacio que surge entre los hombres, sino que se transfiera a un proceso que se realiza a espaldas del hombre que actúa, y que opere ocultamente, más allá del espacio visible de los asuntos públicos. El modelo de este concepto de libertad es el de un río que fluye libremente, y para el que cualquier interposición representa una arbitrariedad que frena su fluir.

O projeto Rádio Nikosia, a associação dos moradores da Barceloneta, as memórias da senhora da lavanderia, as palmas gitanas, a arte diária de sobrevivência dos senegaleses, a sonoridade dos músicos de rua, bem como toda produção 
de resistência viva a um projeto privatista de uma Barcelona guapa pode ser considerado como componentes desse rio que flui liberdade. São muitos elos de uma cadeia que agenciam o que podemos chamar de acontecimento. Uma outra forma de beleza fruto de uma produção coletiva que constrói uma Barcelona plural que ainda resiste à beleza que se tenta impor e vender. Esta Barcelona resiste!

\section{Notas}

${ }^{1}$ Para mais informações sobre Contrabanda FM 91.4: visitar a página de internet www.contrabanda. org, ou pelo correio eletrônico contrabandafm@contrabanda.org.

${ }_{2}^{2}$ Para mais informações sobre Radio Nikosia: visitar a página de internet www.contrabanda.org, ou pelo correio eletrônico info@radionikosia.org

${ }^{3}$ Para o texto completo em espanhol ver: http://w3.bcn.es/fitxers/ajuntament/consolidadescast/ convivencia.217.pdf

${ }^{4} \mathrm{O}$ Ayuntamiento é a administração pública da cidade de Barcelona, o que na organização sociopolítica brasileira chamaríamos de Prefeitura.

${ }^{5}$ Para texto completo em espanhol ver: http://www.ben.es/paisatgeurba/castella/descargar/guia. pdf

${ }^{6}$ Para mais informações sobre Che Sudaka ver: http://www.chesudaka.com

${ }^{7}$ Para mais informações sobre Microguagua ver: www.myspace.com/colectivomicroguagua

\section{REFERÊNCIAS}

14 KILÓMETROS. Direção: Geraldo Olivares. Espanha: Explora films, Wanda Visíon S.A., 2007. 1 DVD (95 min). Gênero: drama. Tipo: longa-metragem, color.

ARENDT, H. A condição humana. 10. ed. Rio de Janeiro: Forense Universitária, 2003.

- ¿Qué es la política? Barcelona: Paidos, 1997.

BARCELONA (Cidade). Ordenanza de medidas para fomentar y garantizar la convivencia ciudadana en el espacio público de Barcelona. Aprobación por el Plenario del Consejo Municipal del Ayuntamiento de Barcelona, en sesión de 23 de diciembre de 2005. Publicación en el BOP de fecha 24/1/2006. Disponível em: $<\mathrm{http}: / / \mathrm{w} 3 . \mathrm{bcn} . \mathrm{es} /$ fitxers/ajuntament/consolidadescast/convivencia.217.pdf $>$ . Acesso em: 15 maio 2009.

. Barcelona, posa't guapa. Ayuntamiento de Barcelona. Disponível em:

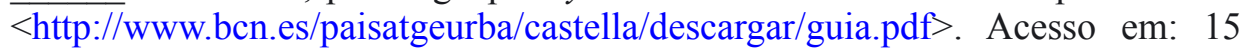
maio 2009.

CABRAL, K. V. La belleza es tu cabeza 1. 2009. 1 fotografia. Disponível em: $<\mathrm{C}: \backslash$ Users $\backslash$ Károl $>\mathrm{e}<$ Márcio $\backslash$ Imagens $\backslash$ la belleza es tu cabeza 1>. Acesso em: 22 abr. 2009.

. La belleza es tu cabeza 2. 2009. 1 fotografia. Disponível em: $<\mathrm{C}: \backslash U$ sers $\backslash$ Károl> e $<$ Márcio Imagens $\backslash$ la belleza es tu cabeza 2>. Acesso em: 22 abr. 2009. 
CABRAL, K. V. Barcelona posa 't guapa. 2009. 1 fotografia. Disponível em: $<$ C:। Users\Károl> e <Márcio\Imagens\Barcelona posa’t guapa>. Acesso em: 22 abr. 2009.

CABRAL, K. V.; BELlOC, M. M. Rádio Nikosia. Barcelona. Programa transmitido pela rádio Contrabanda FM. Projeto iniciado no ano de 2003.

BAUDELAIRE, C. O Pintor da Vida Moderna. In: . A modernidade de Baudelaire. Apresentação de Teixeira Coelho. Tradução de Suely Cassal. Rio de Janeiro: Paz e Terra, 1988. p. 159-221.

BENJAMIN, W. Magia e técnica, arte e política: ensaios sobre literatura e história e cultura. 7. ed. São Paulo: Brasiliense, 1994. Obras Escolhida, v. I.

DELGADO, M. Sociedades Movedizas: pasos hacia una antropología de las calles. Barcelona: Anagrama, 2007.

LICHTENSTEIN, R. Cabeça de Barcelona. 1992. 1 escultura.

PALOMBINI, A. Acompanhamento terapêutico na rede pública: a clínica em movimento. Porto Alegre: UFRGS, 2004.

SANTOS, M. Pensando o espaço do homem. 5. ed. São Paulo: Universidade de São Paulo, 2004.

VALADARES, J. C. Clínica psicanalítica e modernidade. Revista Psicologia Clínica, Rio de Janeiro, v. 15, n. 1, p. 201-206, 2003. Departamento de Psicologia da Pontifícia Universidade Católica do Rio de Janeiro. Centro de Tecnologia e Ciências Humanas.

Recebido em: maio de 2009

Aceito em: julho de 2009 